\title{
LA DESIGUALDAD SOCIAL Y LA COLONIALIDAD DEL PODER. CONSIDERACIONES TEÓRICAS Y EPISTEMOLÓGICAS
}

\section{SOCIAL INEQUALITY AND COLONIALITY OF POWER. THEORETICAL AND EPISTEMOLOGICAL CONSIDERATIONS}

\author{
Juan Alberto Huaylupo Alcázar*
}

RESUMEN

Este ensayo es una reflexión crítica de la acuciante problemática de la desigualdad que se agudiza en el presente globalizado. El trabajo se inscribe en el reconocimiento del derecho que asiste a la población ciudadana a no ser discriminada, vivir acorde con sus necesidades $y$ a realizarse individual $y$ socialmente, aspectos sobre los cuales existe cada vez una mayor sensibilidad nacional e internacional, aunque debe mencionarse que los implícitos epistemológicos, teóricos, históricos y culturales, no siempre son coincidentes ni explicitan las condiciones contextuales que viabilizan, reproducen y profundizan la desigualdad entre individuos, clases y pueblos de la aldea global. Aspectos que buscan ser analizados y comprendidos desde una perspectiva relativamente diferente. La multidimensionalidad de la desigualdad determina su complejidad y las diversas posiciones interpretativas limitan la posibilidad de concordar sobre sus causalidades, efectos y medidas que resuelvan una condición social que ha acompañado a la humanidad a lo largo de su historia y que en la actualidad se acrecienta mundialmente.

PALABRAS CLAVE: IGUALDAD * POLÍTICA PÚBLICA * POSITIVISMO * COLONIALISMO * PODER

\section{ABSTRACT}

This essay is a critical reflection about the pressing problem area of inequality becoming acute in the globalized present. The paper is inscribed within the acknowledgement of the right citizens have to not be discriminated, to live pursuant to their needs and to fulfill themselves as individuals and socially. Increasing national and international sensitivity exists about these aspects; yet, it behooves to be mentioned that the epistemological, theoretical, historical, cultural, and other implicit aspects are not always coincidental nor do contextual conditions appear explicitly that make viable, reproduce and deepen the inequality among individuals, classes, and peoples of the global village. These aspects 
are deemed to be analyzed and understood from a relatively different perspective. The multi-dimensionality of inequality determines its complexity and the various positions in interpretation hinder the possibility of finding agreement about the causes, effects, and measures that resolve a social condition that has accompanied humanity along its history and that is presently growing worldwide.

KEYWORDS: EQUALITY * PUBLIC POLIC * POSITIVISM * COLONIALISM * POWER

\section{LA UTÓPICA CONSTITUCIÓN DE LA IGUALDAD}

La desigualdad es una situación con la cual ha vivido la humanidad a través de los tiempos, aun cuando no siempre ha sido apreciada como un problema social o político en aquellos contextos donde se carecía de derechos. En la aldea global contemporánea perduran las relaciones internacionales y la configuración del poder, creadas con la Segunda Guerra Mundial (IIGM), a pesar de las transformaciones contextuales de las naciones en la sociedad global contemporánea.

La idea de la igualdad tiene en la Revolución Americana y la Revolución Francesa sus antecedentes que inauguraban en el mundo la igualdad formal entre los individuos. Las revoluciones no solo transformaron sus espacios sociales, sino que la igualdad se convertía en la idea de justicia y equidad entre los individuos convertidos formalmente en ciudadanos del mundo. Las revoluciones fundaron la idea de igualdad jurídica en sus espacios políticos, pero también constituyó la inauguración política del sistema económico capitalista mundial.

La idea de igualdad formal es aún el horizonte ideológico de las relaciones políticas y económicas entre individuos y sociedades desiguales, la cual impregna gran parte de las relaciones en contextos sociales que se definen como democráticos y capitalistas, así como entre individuos e incluso en quehacer investigativo y científico. La igualdad en la desigualdad es el dilema que no se logra ni puede resolverse en una sociedad y economía que se sustenta en la generación, profundización y reproducción de la desigualdad. De esta manera, aumenta el hambre, la desocupación y la miseria en el mundo, así como aumentan los millones de migrantes, desplazados y refugiados de sus espacios de vida.

A pesar de su inconsistencia real, el horizonte ideológico de la igualdad es en nuestros días una preocupación incesante en el mundo ante las extraordinarias dimensiones que adquiere la desigualdad y que en parte revela la vulnerabilidad económica y política de un sistema que desprecia a los trabajadores y que se escuda en la igualdad para profundizar la desigualdad en las poblaciones. El presente ensayo pretende analizar algunas de las dimensiones donde se expresa la paradoja igualdad/desigualdad, así se discutirá su presencia desde el ámbito de su gestación originaria, la investigación y la ciencia, la política, la economía, así como, se presentarán algunos prejuicios en torno a los movimientos sociales.

\section{LA DESIGUALDAD ¿¿UNA PROBLEMÁTICA POR LA IGUALDAD?}

La desigualdad social es una preocupación creciente en análisis y debate mundial, abordada por estudiosos como Joseph Stiglitz (2012), Göran Therborn (2015), Amartya Sen (2001), Bernardo Kliksberg (2007) y Manuel Garretón (2012), y entidades internacionales como la Comisión Económica para América Latina y el Caribe (CEPAL, 2012, 2014a, 2014b y 2016), el Banco Mundial (2016) o el Banco Interamericano de Desarrollo (1999 y 2008). En el siglo XVIII, se estudió este concepto para indagar sobre sus orígenes. En el siglo XIX, se incluye en el estudio de clases sociales $y$ en el siglo $x x$, se presenta en el análisis de la estructura, la estratificación 
social y la política pública, dimensión analítica que aún perdura.

La evidencia histórica de la desigualdad y la confluencia de sus estudiosos desde distintas perspectivas teóricas e ideológicas ha derivado en diversas formas de interpretarla. En algunas investigaciones ha sido analizada como consecuencia sistémica e histórica de la sociedad y economía; en otros casos contemporáneos, como una problemática derivada del diseño y la ejecución de las políticas públicas y de acuerdos internacionales.

La desigualdad es infame en un sistema que formalmente postula la igualdad política y la democracia entre las personas y sociedades. Sin embargo, habría que hacer algunas reflexiones al respecto: ¿las luchas sociales a lo largo de la historia han sido por la igualdad?, ¿acaso el anhelo individual o social es por poseer idénticas capacidades, recursos, bienestar o vida que tienen otros individuos o sociedades?, ¿existen las condiciones que hagan viable la conquista de la igualdad social en un sistema desigual?, ¿acaso la igualdad social no es un atentado contra la pluralidad $y$ la diversidad social? o ¿los enfrentamiento sociales en la historia de los pueblos del mundo han tenido el propósito de eliminar las clases sociales para la instauración de la igualdad sin explotación ni exclusión?

Las manifestaciones y estudios contra la desigualdad expresan el descontento y la desafección ciudadana ante estructuras sociales $y$ de poder clasistas, así como, los fracasos de la institucionalidad pública por las carencias que limitan e impiden la realización personal y social de las mayorías nacionales. La desigualdad producto de la explotación del trabajo, la exacción y desfalco de las riquezas de los pueblos es una realidad opresiva de las masas en el mundo y es la fuente de conflictos que conmueven la economía y la política en las sociedades.

Estas consideraciones han derivado en posicionar la idea que las luchas tienen por finalidad la conquista de la igualdad social, aun cuando es una categoría general frente a la heterogeneidad de causalidades que la originan, a decir de Ronald Dworkin (2003), "La igualdad es la especie en extinción de los ideales políticos" (p. 11). La desigualdad es evidente en las sociedades y no requiere estudios para evidenciarlo, quizás habría que preguntarse: ¿a qué luchas por la igualdad se refieren quienes propugnan la igualdad? ¿igualdad de qué?, ¿̇en qué?, ¿entre quiénes?, como lo hacen Amartya Sen (1979), Gerald Cohen (1996) y Norberto Bobbio (2009), de este modo se hacen mediciones sobre la igualdad económica, de derechos, de recursos, de capacidades, de oportunidades, de género o sobre igualdad de calidad de vida, bienestar, salud, educación, etc., y sus relaciones con la libertad, la democracia, la justicia o el derecho a rebelarse ${ }^{1}$. En la actualidad abundan los estudios cuantitativos sobre la desigualdad, los cuales omiten las cualidades que dan significación a las cantidades y que implícitamente podrían inferir erróneamente determinaciones $y$ efectos similares.

Los Objetivos del Desarrollo Sostenible aprobados por la Organización de las Naciones Unidas (ONU, 2015; CEPAL, 2016), sintetizan los anhelos de bienestar, seguridad, justicia, etc. ${ }^{2}$, que la sociedad global niega a gran parte de la población mundial. Son postulados inspirados contra las iniquidades, exclusiones y toda forma de discriminación a las personas en el mundo, sin embargo, sus efectos trascienden la situación y condiciones del presente para constituirse en una utopía que requiere una profunda transformación global, cuyo horizonte no es aún posible prever. El propugnar la igualdad en un sistema que crea, reproduce y expande desigualdad, es una contradicción, no obstante, se elude las determinaciones sistémicas, para centrarse en las mediciones de formalizados indicadores, los cuales podrán equipararse

1 Desde la visión liberal, el ser desigual es un derecho, producto de las iniciativas individuales, razón por lo cual discrepan con prácticas igualitarias que impulsan los Estados sociales (Friedman y Friedman, 1980). Los liberales reclaman la libertad para ser diferentes o desiguales con respecto a los otros, trabajadores, excluidos y pobres.

2 Costa Rica es el primer Estado del planeta que suscribe su compromiso por los Objetivos del Desarrollo Sostenible y que orienta su política pública según su plan quinquenal de desarrollo nacional. 
cuantitativamente, sin distinción de sus contenidos ni de la significación, social, histórica o cultural en las comparaciones cuantitativas.

El cuestionamiento a la desigualdad, no es el referente negativo de su par dialéctico, como tampoco la igualdad puede ser explicada a través de la desigualdad. La igualdad es una entelequia compleja, insuficientemente explorada, además de ser una abstracción de difícil consenso que no tiene un claro, preciso ni consistente antecedente en la historia de los pueblos del mundo, pero en la actual sociedad capitalista se reivindica, aun cuando convive y se sustenta en la reproducción social de la desigualdad.

La desigualdad tiene una regularidad histórica a través de los tiempos en las relaciones sociales $y$ es posible afirmar que es inherente de las personas y colectividades diversas y plurales, así como lo es la historia y la cultura que modelan inéditamente la situación, actuación $y$ pensamientos en las sociedades. La identidad social implica diversidad en los horizontes históricos de las poblaciones que subordinan $y$ otorgan contenidos particulares a las formas instrumentales. Las luchas justas de los pueblos y trabajadores no son por la igualdad, no son confrontaciones por las transformaciones radicales de la sociedad ni por la erradicación de las relaciones de explotación, regularmente son luchas por mejores condiciones de vida, de trabajo, por la justicia, el bienestar y la democracia $^{3}$, las cuales no son iguales entre sociedades, como tampoco obedecen a idénticas problemáticas ni similares capacidades orgánicas de las poblaciones o prácticas individuales.

Si bien, la equidad no supone transformación radical de la sociedad, la igualdad tampoco implica la transformación. En el presente, ninguna organización reivindica la igualdad ni forma parte de ninguna plataforma política 0 ideológica. Las luchas clasistas y las ideas por

$3 \quad$ En determinados contextos históricos, los cambios por reducir la inequidad en el sistema han sido fruto de cruentas confrontaciones $y$ han constituido cambios profundos en la desigualdad de las relaciones sociales, pero no han sido antagonismos que buscaran la eliminación de las desigualdades, ni propugnar la igualdad en sus espacios sociales. la eliminación del Estado fueron acciones que buscaron la transformación de las sociedades, sin embargo, la transición hacia una sociedad sin clases ha sido una historia de fracasos y decepciones políticas. El triunfo de la revolución bolchevique en 1918, no reivindicaba la igualdad, como tampoco lo han hecho las revoluciones socialistas en el mundo, ni sus regímenes triunfantes.

Afirmar que la igualdad es una construcción imaginaria, ideal o utópica, mientras que la desigualdad es concreta, transparente y evidente, no significa una postulación fatalista de la posibilidad de alcanzarla, no porque se crea que la explotación, la exclusión y la inequidad deban ser infinitas de unos contra otros, sino porque no es posible la igualdad de individuos y sociedades en la diversidad cultural, histórica, de anhelos y construcción colectiva, menos aún en un sistema que ha legalizado y legitimado la explotación del trabajo y la apropiación privada de los excedentes generados socialmente.

\section{LA DESIGUALDAD DESDE LA DIMENSIÓN CUANTITATIVA}

La igualdad y desigualdad son categorías que regularmente son usadas para describir $y$ establecer las diferencias entre individuos, segmentos sociales, clases o sociedades, de ahí que los estudios sobre esta temática se encuentren acompañados de prolijas comparaciones para establecer contrastes entre realidades descontextualizadas, como pueden apreciarse en trabajos de la CEPAL (2012, 2014a, 2014b, 2015,), Ferranti, Perry, Ferreyra y Walton (2005), Sen (2000, 2001) y Bernardo Kliksberg, (2010), entre otros. De este modo, las descripciones empíricas y cuantitativas no son explicadas, solo son usadas para justificar posiciones de política pública y acciones particulares a los Estados por parte de entes internacionales u otros Estados del poder mundial.

Al parecer no interesan los orígenes de las diferencias entre individuos, pueblos o Estados, se asume que la desigualdad es la responsable de todas las injusticias, así es posible afirmar que la "desigualdad mata" (Therborn, 2015), deteriora la calidad de vida, enferma, desintegra, crea pobreza, miseria, hambre o 
ignorancia (Kliksberg, 2002). Las descripciones son transformadas en "explicaciones", donde las causas que originan las desigualdades y sus consecuencias directas son ignoradas, solo interesa destacar las diferencias al equipararlas con otras realidades, aun cuando las peculiaridades de especificas realidades no son universales ni comparables.

La alimentación, la vestimenta, la forma de vida, los ingresos, la vivienda, la educación, etc. son contrastables a pesar de responder a formas culturales, históricas y estructurales propias de cada realidad. Suponer que puedan existir indicadores iguales, que representen $y$ tengan idénticas significaciones en espacios sociales distintos, son suposiciones alejadas de toda experiencia y evidencia, así como son vacías de contenido. Las diferencias de los fenómenos, procesos o en general entre realidades, son obvias $y$ no requieren mediciones para establecer la heterogeneidad y desigualdad entre sociedades. Imaginar relaciones mecánicas o estandarizadas, sin historia, cultura o formas de vida y creencias entre las personas, pueblos $y$ sociedades, es sin duda un absurdo, como seguramente lo será para quienes no creen que cada suceso empírico es peculiar e inédito, cuyas determinaciones no son idénticas ni producen idénticos resultados.

Este desencuentro entre lo cuantitativo y la explicación de lo real, no es científico, es ideológico y epistemológico, consideración que limita el diálogo y la comprensión de la complejidad del fenómeno social. Hacer creer que el trabajo científico es una labor que busca contrastar datos y mediciones de objetos de estudio, es retroceder siglos en la historia de la ciencia, al falsificar y degradar su papel en la comprensión y explicación de los fenómenos reales. Afirmar que una realidad es distinta a otra, es una obviedad que no requiere ser explorada, como tampoco el determinar la magnitud de los contrastes o semejanzas porque no tienen igual significación, como tampoco idénticas determinaciones ni efectos en cada contexto contrastado.

Las mayores o menores diferencias, si se desconocen sus determinaciones causales, no significan mayor o menor satisfacción o dramatismo en la situación de las personas o los pueblos comparados. El conocer no es equivalente a la medición ni a la comparación. Las descripciones y mediciones que ignoran la teoría, la epistemología y las peculiaridades de los fenómenos naturales, sociales o históricos son auténticas regresiones en la explicación científica, como se desprende de los estudios de la CEPAL (2012), Sen (2001), Ferranti et ál. (2005), Stiglitz (2012), entre otros.

Creer que las diferencias cuantitativas son lo concreto, lo objetivo, lo que hay que resolver y que los análisis y el estudio de sus determinaciones causales son lo especulativo, es suponer que los datos existen autónomamente, que son la realidad misma y que no necesitan del entorno para comprenderlos ni para modificarlos. En esta perspectiva, lo central es construir los datos y ello será un asunto fundamentalmente metodológico, técnico e instrumental. Así, modificar las magnitudes de la desigualdad se convierte en el propósito de quienes han endiosado a las estadísticas sin tomar en cuenta las fluctuaciones de las realidades y la significación dinámica de lo medido y contrastado. Los datos sin realidad son fraudes de cientificidad y objetividad. Es una contradicción considerar como científica una actividad que anula toda interpretación, explicación o compresión de las realidades.

Lo tangible está cargado de subjetividad al establecer qué, cómo y dónde se debe observar; ¿cuáles son valoraciones destacadas o los indicadores y datos que deben son usados?; ¿cómo son colectados, procesados y cuantificados? y ¿cómo deben ser interpretados? El privilegio de las descripciones y las cuantificaciones niegan todo análisis, dado que desprecia toda exploración intelectual o comprensión sobre lo estudiado. Esta práctica empirista transforma a los sujetos en objetos de las técnicas usadas al describir y cuantificar, a la vez que sustituye las relaciones de interdependencia y causalidad de procesos integrados en simples asociaciones de contigüidad, sin nexo alguno, con lo cual se podrían registrar correlaciones irreales o absurdas, como cuando 
se afirma que "cada vez que canta un pájaro muere un indio"4.

Esta orientación es una tendencia predominante en el quehacer de los estudios políticos contemporáneos, que asumen que la desigualdad es evidente y manifiesta que no requiere efectuar exploraciones sobre la totalidad social, las complejidades epistemólogicas, teóricas o históricas en torno de la desigualdad ni sobre la reproducción de las sociedades. El pragmatismo utilitarista solo necesita aplicaciones para reducir los contrastes de desigualdad, aun cuando sean de carácter metodológico, porque de ese modo creerán que las realidades se aproximan a la igualdad.

De este modo, se falsifican las realidades con cantidades inventadas estadísticamente. Así, al revelarse las cantidades y tasas comparativas de analfabetismo, hambre, desocupación, pobreza, exclusión, enfermedad o muerte de personas o poblaciones, sirven como parámetros manipular las cifras para ampliar o reducir las brechas entre los espacios sociales comparados, independientemente de su contexto $y$ determinaciones particulares. El supuesto de esas comparaciones es alcanzar mediciones similares, asumiendo que representan e implican iguales procesos sociales. No obstante, en el supuesto imaginario que las mediciones fueran similares, no implica igualdad de condiciones y situaciones en los espacios comparados, dado que, existen muchos elementos asociados a los fenómenos comparados, pero no tomados en cuenta ni registrados.

La pobreza, por ejemplo, es una categoría histórico moral, cuyo registro es posible hacerlo en todos los países, sin embargo, serán particulares para cada contexto, pues la persona en condición de pobreza en un ámbito específico, no lo será en otro espacio o se ubicará en extrema pobreza en otro espacio social. Los indicadores de medición de la pobreza no serán los mismos para cada espacio social, así como, la significación de los indicadores variarán en cada espacio y tiempo. El ignorar

$4 \quad$ En un mito maya, se hace referencia al ave tecolote o tunkuluchú, que anda sola $y$ vive en las ruinas, cuyo canto anuncia la muerte. las realidades en su integridad es también una limitación para determinar los indicadores que definen una problemática particular, así como convierten a estos en solo una construcción instrumental y técnica estandarizada, con formalidad cuantitativa, pero con un contenido desconocido.

Desde la visión empirista, los datos cobran autonomía y se les atribuye validez por sí mismos, luego en las mediciones de la desigualdad se pretende bajar las brechas existentes entre individuos, grupos y sociedades en razón de patrones idealmente prefigurados o de realidades que imaginan ser modelos a emular. Así, la desigualdad registrada se convierte en un asunto estadístico susceptible de ser controlado, con lo cual es posible manipular metodológicamente las tendencias y perspectivas que amplían o reducen cuantitativamente las desigualdades entre poblaciones y pueblos.

Esta posición es la reedición de viejos argumentos que en la década del 60 del siglo pasado se enunciaban sobre el subdesarrollo con respecto del desarrollo, había que tener iguales o similares magnitudes en los indicadores seleccionados en las comparaciones, ya sea en educación, ingresos, población rural, principales actividades económicas, etc. El conocimiento de las realidades, las teorías o las explicaciones de los fenómenos concretos eran omitidos para destacar exclusivamente el contraste estadístico mientras que los conocimientos de las realidades eran ignorados.

La pretendida objetividad empirista es por el contrario la subjetivación de los fenómenos de la realidad, al suponer que los indicadores pueden representar a los fenómenos, aun cuando surgen de la imaginación, prejuicios o creencias sobre qué, por qué medir o cómo especular. Desde esta perspectiva, los desconocimientos de las realidades impiden comprenderlas, solo medirlas es una simplificación de la complejidad, dinamismo y diversidad de los fenómenos. La materialización cuantitativa de variables e indicadores son concreciones metodológicas de la subjetividad positivista, las cuales son asumidas como absolutas, exactas e invariables (Zemelman, 1989). 
Los datos son registros parciales y relativos de la realidad (Huaylupo, 2008), su significación no está dada por sí mismos, son dependientes de las formas metodológicas e instrumentales como se han construido, de las concepciones interpretativas o teóricas que explícita o implícitamente se sustentan, del contexto con los que se relacionan y que les dan específicas significaciones. Asimismo, los datos no son absolutos ni tienen validez más allá del momento de su registro $y$ de las concepciones $y$ métodos usados en su construcción. De tal forma que imaginar los datos estáticos y proyectarlos para otros tiempos es insustentable teórica, empírica y epistemológicamente.

La riqueza de la diversidad y complejidad de las realidades no se representan en su totalidad con datos estáticos ni en los implícitos y supuestos de los indicadores usados, a la vez que ignoran el dinamismo de los fenómenos que modifican los datos, se relativizan y pierden la significación otorgada. El comparar contextos diferentes con idénticas metodologías, variables e indicadores, tendrán resultados cuantitativos distintos y sus significaciones serán diferentes ¿Por qué no se hacen contrastes a través del tiempo de la propia realidad estudiada para determinar sus cambios $y$ sus determinaciones en cada contexto histórico particular? No es ingenuidad no hacer estudios sobre la desigualdad en sociedades particulares, hay intencionalidades ideológicas concretas. Así, por ejemplo, se validan los estilos de vida de otras sociedades como una vana invitación a ser como ellas, o dicho de otro modo, despreciar nuestros estilos de desarrollo o inferir que no existe otro camino para el bienestar y el desarrollo de las personas que la adopción de patrones de vida impuestos por la colonialidad del poder, o la condena a tener nuestra propia historia y desarrollo, así como ocultar determinaciones históricas, estructurales, políticas o económicas en las coyunturas comparadas.

El empirismo tiene en la especulación estadística su medio de justificación epistemológica, cuya función es la descripción y especulación cuantitativa. Tiene muchos adherentes por los prejuicios sociales y educativos en favor de la matemática, aun cuando no explica ninguna realidad es apreciada como incontrovertible, consideración que también se valora en las ciencias exactas o duras, como suelen erradamente denominarse ${ }^{5}$. El registro cuantitativo de la matemática en la investigación ha falsificado la concepción misma de la investigación y la ciencia.

Las aplicaciones estadísticas sobre la desigualdad han llevado a estimar que reduciendo los contrastes en los valores de las variables son logros en equidad, democracia y libertad, aun cuando esas variaciones sean el resultado de cambios metodológicos y no del cambio de las realidades. Esas cantidades sustituyen a las realidades, las cuales podrán ser interpretadas de modos diversos según la manipulación interesada de las cifras. La posición epistemológica empirista renuncia a comprender y explicar los fenómenos que mide y compara (Kolakoswski, 1970).

Así, las realidades se revelan como idénticas en sus representaciones cuantitativas, por ello se cree que los indicadores tienen el mismo significado, obedecen a iguales determinaciones y consecuencias ¿Cómo suponer que las inequidades de realidades distintas se puedan expresar con los mismos indicadores y puedan tener igual significación?, ¿acaso se imagina que las realidades son idénticas y que la historia, cultura o el devenir peculiar de las relaciones y procesos sociales, no marcan diferencia alguna que limite la comparación? Suponer que no existen diferencias entre sociedades niega toda consideración teórica, empírica y de sentido común sobre las sociedades.

A pesar de las obvias observaciones, cuya aceptación quizás sea por su simplicidad, es frecuente apreciar en los creadores de datos que con encuestas en serie o con el comercio de bases de los datos, consideran a las personas

$5 \quad$ La formalización matemática tiene una estructura y una lógica propia de una disciplina creada por el ser humano, la cual no tiene correspondencia con la forma alguna como se estructura la complejidad de las realidades que cuantifica. La consideración de lenguaje de la ciencia es un prejuicio que aprecia los resultados como lógicos y absolutos, que erróneamente se creía, en el pasado, eran cualidades de la ciencia. 
y sociedades como si fueran iguales. Así, en el ámbito de la salud, los tratamientos están determinados por los laboratorios mundiales que producen $y$ venden fármacos, no por la naturaleza particular de los enfermos, de sus patrones genéticos o de la especificidad de sus formas de vida $y$ trabajo.

Las personas con padecimientos en su salud son tratados de modo estandarizado, según los laboratorios mundiales y también por la experiencia o conocimientos de los profesionales de la salud. No existe, al menos en la medicina alopática, un tratamiento particular a la salud ante padecimientos particulares. La salud pública está manipulada por los laboratorios mundiales que emplean millones de dólares para crear fármacos que solo palian los efectos de enfermedades $y$ sus secuelas esclavizando a los enfermos en una interminable red mercantil. En las ciencias de la salud, la experimentación continúa siendo el método preferente para la validación y comercialización generalizada de medicamentos, en laboratorios o en la prescripción de fármacos por profesionales liberales, los cuales son remunerados para hacer un seguimiento de sus efectos en pacientes, esta práctica es frecuente en los servicios de la salud pública y privada de muchos países.

De modo similar, los usos masivos de las encuestas de opinión, es otro ejemplo que supone igualdad de comportamientos, pensamientos $y$ acciones entre los individuos y sociedades. Así, las muestras de personas que son entrevistadas, para conocer las preferencias de voto de candidatos a alcaldes o presidentes de las repúblicas, o del consumo de mercancías, tienen la característica de contrastar diversas encuestas aplicadas a personas y grupos distintos para afirmar y concluir que tales candidatos o mercancías han aumentado o disminuido su aceptación ciudadana, asumiendo que el comportamiento de una muestra tiene una opinión o comportamiento similar o igual al universo poblacional.

Las comparaciones entre sociedades es una forma de validar o justificar la colonialidad del poder, de la cultura superior, de la existencia de un modelo que debe ser imitado. La trascendencia dada a la desigualdad, tiene un propósito ideológico y político discriminador y peyorativo con las sociedades que tienen un estilo de vida distinto de las metrópolis capitalistas. Se destaca la desigualdad tal como lo hacen funcionarios internacionales $y$ académicos, que toman como ideal de la igualdad a los países del poder mundial para mostrar una pretendida superioridad del modelo metropolitano del poder capitalista:

...lo «absoluto», aquello que está «por encima de» los sentidos - lo verdadero, lo bueno, lo bello- no es aprehensible, pues nadie sabe concretamente qué es. Sin duda, todo el mundo tiene un concepto de ello, pero cada cual se lo representa en concreto como algo completamente distinto. En tanto que la acción depende de la pluralidad de los hombres, la primera catástrofe de la filosofía occidental, que en sus pensadores postreros desea en último término hacerse con el control de la acción, es la exigencia de una unidad que por principio resulta imposible salvo bajo una tiranía (Arendt, 2015, p.41).

Han transcurrido siglos desde que Leonardo da Vinci (1452-1519) construyera las bases del empirismo, lo que constituía un avance en la ciencia en esos tiempos, sin embargo, los aportes del ayer son obstáculos en el presente. Las consideraciones sobre los fenómenos libres de la subjetividad han quedado petrificados, anquilosados en el pasado, para optar en negar toda subjetividad y desconocer la pertinencia del pensamiento explicativo para comprensión de los fenómenos. Consideraciones que han derivado en la magnificación de los procesos técnicos que manipulan datos, aun cuando la construcción del dato está plagada de consideraciones valorativas o subjetivas, se autocalifica como objetiva y científica.

Las discusiones sobre la ciencia libre de valores es una vieja discusión, que han sido zanjadas epistemológicamente (Gouldner, 1979), pero no aceptadas ideológicamente, así como el quehacer científico ha sido valorado como libre de condicionantes de su época, como lo pensaba Augusto Comte (2002), al considerar 
que la ciencia conducirá al mejor de los mundos posibles. La subjetividad apreciada como lo inexistente fácticamente o lo imaginado sin concreción alguna ha sido apreciada como ajena a la ciencia ${ }^{6}$, absurdo que fue fomentado en el sistema educativo, que se encubre en una aparente indiferencia, pero ¿habrá alguna obra humana 0 pensamiento libre de subjetividad?

Así, los datos como expresión de una supuesta objetividad y de cientificidad son proyectados, se crean modelos matemáticos y cuanta interrelación cuantitativa se imaginan, como si fuera la propia realidad. La objetividad del empirismo no se revela a sí mismo como una posición epistemológica, filosófica o participe de una concepción de mundo (Kolakowski, 1981), pero no admitirlo no significa que no lo posea ni es compensado al encubrirse en la observación y la matemática. Esto es, se sustenta en una disciplina formal inventada por el ser humano: la matemática, luego impregnada de subjetividad y con una visión particular del universo, distinta a las cosmovisiones y mediciones de los aztecas, mayas, incas y otras formas de cálculo que ha conocido la humanidad. Al respecto, las palabras del poeta José Bergamín son ilustrativas sobre este dilema: "Soy subjetivo, ya que soy sujeto. Si fuese objetivo, entonces sería un objeto".

La experimentación, el dato y la cuantificación como fuentes de la verdad constituyen en el presente auténticas barreras que impiden comprender las realidades, sus relaciones $y$ complejidad. El conocimiento científico no está alejado de las valoraciones y pensamientos de la época, sin embargo, las regresiones cognoscitivas no son admisibles, ni los actos humanos individuales $y$ colectivos son productos de reacciones mecánicas de cosas. La subjetividad existente forma parte integral de las realidades, inclusive, modelan las dimensiones tangibles que se miden $y$ describen.

Los tiempos de polémicas que contradicen al positivismo no terminan y continúan

$6 \quad$ La crítica del positivismo en el pasado contra las interpretaciones religiosas (Kolakowski, 1981), ha endiosado en el presente a los datos o a las formas especulativas y metafísicas de las estadísticas que interpreta como datos. incólumes las posiciones epistemológicas empiristas y posiblemente se han fortalecido en el presente liberal con las prolíficas técnicas cuantitativas. La funcionalidad del empirismo al statuo quo impide la visión de totalidad, para detenerse solo en la parte como el centro de su medición y comparación. De este modo, se suprime el conocimiento renovador y crítico, se absolutiza, se hace conservador y la ciencia se degrada a sus periodos observacionales y descriptivos como si nada hubiera pasado a través de los siglos. La ciencia y la libertad cognoscitiva están atrapadas en una concreción inventada por el endiosamiento cuantitativo o tecnocrático (Habermas, 1984). La pertinencia del empirismo no es por consideraciones cognoscitivas ni por el desarrollo epistémico, sino por determinaciones políticas e ideológicas funcionales al poder.

Parece absurdo que estos ejercicios que solo describen parcialmente, que no explican ni son parte de la labor científica, sean hechuras de prestigiosas personalidades e instituciones, contraviniendo el estado del conocimiento científico y epistemológico del presente. No obstante, las cifras son usadas como entidades simbólicas donde se destaca lo bien que están algunas sociedades frente a la indignante situación de otras. Esto implica que hay una velada intencionalidad ideológica que denigra a unos Estados y sociedades frente la situación y poder de otros. La colonialidad del poder se expresa en las cifras de aparente objetividad $y$ neutralidad.

\section{IGUALDAD Y ESTADO DE DERECHO}

Las triunfantes luchas sociales de la Revolución Americana y la Revolución Francesa que inauguraron políticamente el capitalismo con el reconocimiento de la igualdad individual, política y la ciudadanía son logros truncados en sus espacios y en la actualidad enfrentan procesos de regresividad creciente, aun con formas jurídicas igualitarias. El pasado y el presente en igualdad jurídica, ponen en evidencian el no haber tenido la fuerza social, la consistencia ni la continuidad política para garantizar el respeto de la realización igualitaria de las personas y los pueblos.

Las fuerzas económicas, ideológicas y políticas que reproducen pobreza e iniquidad, 
están incólumes en un sistema que les garantiza una permanente relación desigual y contradictoria. Las revoluciones burguesas inauguraban políticamente la condición necesaria para las personas, pero también necesario para el capitalismo, sobre las cenizas de regímenes caducos en sociedades sin derechos, pero no para consagrar sus enunciados igualitarios en sus estructuras sociales. La igualdad era el contraste revolucionario frente a una desigualdad configurada social, cultural e históricamente, sus triunfos formalizaron una igualdad formal en los espacios sociales convulsionados, como un principio emancipador pionero en la desigualdad social, como un modo para plasmar el deseo, utopía o la ilusión especulativa por una mejor vida para los desiguales. Es una paradoja enarbolar la igualdad en la desigualdad, pero sin duda, la contradicción de este derecho formal, significó un avance en la historia de las relaciones sociales, en el que solo la tiranía tendría vigencia, con lo cual se establece una dicotomía, ¿se está frente a una igualdad formal en el contexto de una tiranía real o es una tiranía regulada, limitada o negociada por la igualdad formal?

La igualdad de oportunidades o la equidad es la posibilidad de acceder a los derechos, recursos, servicios y posibilidades de realización individual $y$ social que otros poseen, pero en un contexto de desigualdad y sin poder político. Esta consideración es paradójica dado que se enuncian derechos, pero sin generar ni garantizar las condiciones para el acceso $y$ beneficios de dichos derechos, libertades y capacidades de los subalternos. Afirmar que la equidad está garantizada con la igualdad de los derechos humanos consagrados internacionalmente $y$ plasmados en las constituciones nacionales ${ }^{7}$, es un supuesto que imagina un mundo regido por patrones jurídicos por encima de toda

$7 \quad$ Las leyes han dejado de ser mandatos en favor del interés general de la ciudadanía y la nación en los tiempos del liberalismo, para ser en muchos casos imposiciones para el beneficio privado que deben ser acatadas por los otros. Las dictaduras en la actualidad tienen en las leyes los instrumentos que justifican la dominación e incluso se han convertido en la fuente para cuestionar, relativizar o derrocar poderes sociales legales y legítimos. injerencia social y política $^{8}$, sin evidencia alguna en la desigualdad de las sociedades $y$ aun cuando se encuentren regidos por constituciones nacionales que tienen igual origen o influencia ideológica y política.

La normatividad jurídica nacional e internacional contemporánea es requisito necesario en la mundialización de las sociedades $y$ los Estados de derechos porque constituyen puntos de partida para el establecimiento de las relaciones, así como para el reconocimiento de los derechos conquistados, los cuales otorgan legitimidad social a las pautas normativas y proporcionan los fundamentos de las relaciones sociales. No obstante, habría que señalar que regular la igualdad entre desiguales en sociedades inequitativas y contradictorias, garantizan relaciones inestables, conflictivas y reguladas por consideraciones más allá de aspectos normativos. Ergo, no existe garantía de respeto y amparo a los derechos conquistados por la ciudadanía y los pueblos.

La formalidad jurídica necesaria para la defensa de las conquistas sociales no es efectiva. Ha puesto en evidencia la vulnerabilidad del poder estatal para determinar la efectividad de la institucionalidad con el fin de amparar lo público y el bien común; es decir, no es la regulación jurídica la que determina la igualdad, sino las particulares relaciones en la sociedad civil y con el Estado ${ }^{9}$. La debilidad o fortaleza

8 Esta consideración parte del supuesto de que las leyes tienen la capacidad de regular todas las relaciones sociales y cualquier alteración al orden establecido será sancionada y erradicada, de ahí que cuando se producen actos de corrupción, delincuencia, etc., se cree que nuevas leyes o sanciones más drásticas pueden solucionarlas, aun cuando quienes crean $y$ administran las leyes construyen privilegios $y$ beneficios exclusivos $y$ excluyentes. Una ilusión mecanicista que predomina en el sistema jurídico costarricense $y$ en otras sociedades.

$9 \quad$ En la nación norteamericana, a inicios de época republicana, la ley era formalizada luego de ser una práctica aceptada en la cotidianidad en las relaciones en la sociedad y con el Estado, sin embargo, en muchos países se cree que la ley modela todas las relaciones sociales, lo cual es una consideración superficial, razón por la cual muchas de sus pautas son ignoradas o irrespetadas por la imposibilidad de 
del poder estatal para resguardar derechos es dependiente de esta relación, como también de las tendencias conflictivas o de antagonismo en la sociedad civil que deconstruyen y crean políticas y poder político.

El resguardo jurídico a los derechos de los individuos en el sistema jurídico está modelado por la individualización de las relaciones sociales, por la institucionalidad estatal, así como por los vaivenes políticos que en un contexto de desigualdad, es la conservación de las condiciones existentes en la sociedad. En el contexto del sistema capitalista, esta igualdad formal es un derecho que lo propugna la desigualdad. Asimismo, la eficacia jurídica está relacionada con las necesidades y circunstancias en las que fueron creadas las leyes que inciden y cosifican su aplicación a través de los tiempos, pero también está sujeta a la coyuntura y los procesos democráticos de la sociedad.

La efectividad del derecho no se determina por sí mismo son las situaciones y condiciones políticas, ideológicas y económicas imperantes las que viabilizan su cumplimiento. La formalización de derechos igualitarios en distintos contextos o tiempos diferentes obtiene resultados disimiles, a la vez que el dinamismo de los procesos sociales y políticos otorgan pertinencia o consistencia de los derechos formalizados. El sistema jurídico de las relaciones sociales y políticas son validaciones formales políticas del poder como modos para la perpetuación de la desigualdad social o la igualdad entre iguales.

La lucha de los pueblos para eliminar los oprobiosos privilegios entre individuos, clases $y$ naciones son enfrentamientos por la equidad para tener la oportunidad o posibilidad real de

regular prácticas sociales, históricas y culturales de los pueblos. Muchas leyes sirven para amparar intereses privados de quienes las impulsan, legislan y aplican. La magnificación de las leyes está relacionada con la privatización e individualización imperante en las relaciones capitalistas, dado que incluso, el Estado, ente encargado de formalizar las leyes, carece de capacidades institucionales y presupuestales para hacerlas cumplir. El carácter público de las leyes solo es tomado en cuenta en su aplicación, mas no siempre responden a interés $y$ necesidad ciudadana $y$ nacional (Dworkin, 2012). realización individual y social, según las historias, culturas e identidades colectivas. Es la desigualdad la consecuencia de un sistema que la genera y la reproduce, pero no es la equidad lo que la revertirá.

El mejoramiento de la calidad de vida de un pueblo está supeditado a la capacidad redistributiva gestada por los subalternos y las políticas públicas o es el poder social para lograr la estabilidad o la relativa estabilidad en la sociedad, pero no implica el fin de la explotación y de la dominación, por ello la posibilidad de la regresión social y política de lo conquistado colectiva y estatalmente es real y tangible en la sociedad capitalista. La posibilidad real de alcanzar el bienestar en razón de cualidades requeridas por las poblaciones en su contexto, historicidad, cultura y constructos colectivos no supone igualdad. Creer que los patrones de vida de otras sociedades podrán ser también de todas o gran parte de las sociedades está alejada de toda realidad.

La igualdad en derechos entre desiguales es relativa $y$ peculiar en cada contexto nacional y ninguna facultad estatal o privada puede igualar procesos construidos social e históricamente. La pretensión igualitaria sin reconocimiento ni respeto a la pluralidad social es un proyecto totalitario, aun cuando ningún ente ni dictador puede obviar ni superar el contexto social ni el sistema imperante del que forma parte. La reproducción de la desigualdad es un resultado sistémico de la dinámica social.

\section{LA IGUALDAD EN EL DERECHO INTERNACIONAL}

En la Declaración Universal de los Derechos Humanos se encuentra la formalidad jurídica que debe custodiarlos, enunciando una igualdad de dignidad $y$ derechos. Fue un acuerdo internacional en 1948 que tuvo como antecedente la Declaración de las Naciones Unidas (1942) y la Carta de las Naciones Unidas (1945), las cuales constituyen las bases de la fundación $y$ del quehacer de la Organización de las Naciones Unidas desde el 24 de octubre de 1945. Una Declaración Universal en un contexto de fin de la II GM, una de las más sanguinarias que ha conocido la humanidad (Hobsbawm, 1999), como respuesta a la transgresión fascista del derecho 
a la vida, aun cuando todos los contendientes en la guerra son participes de la liquidación física, libertad y de derechos de los individuos, pueblos y sociedades.

Estos enunciados universales, como otros, luego de las conflagraciones sociales, tiene sus antecedentes en la Declaración Inglesa de Derechos (1689), la Declaración de Independencia de Estados Unidos (1776), la Declaración de los Derechos del Hombre y del Ciudadano de la Revolución Francesa (1789), también en épocas anteriores se registraron acuerdos vinculados con los derechos humanos, como el Pacto de los Perfumistas (585 d.C.) y el Pacto de Virtuosos (586 d.C.) acordado por las tribus árabes, o del Cilindro de Ciro (539 a.C.), luego de la conquista de Babilonia por Ciro, el Grande del Imperio de Aqueménida de Persia.

Los acuerdos en favor de la justicia $y$ contra toda forma de opresión son anhelos de las poblaciones del mundo a lo largo de la historia $y$ en los sistemas sociales y políticos conocidos, sobre todo después de conflictos que cobraron ingentes víctimas y como medio para legitimar los resultados de dichas conflagraciones bélicas, o dicho de otro modo, consolidar las desigualdades creadas por los vencedores.

La paz abriga el recuerdo de la guerra.

Así, el siglo de las guerras y la agudización de las desigualdades del mundo (Hobsbawm, 1999), crecen y se expanden en lo que va del presente siglo. Las imposiciones militares y políticas contemporáneas trastocan los regímenes sociales y estatales, así como se crean las bases para la mayor expansión monopólica de las relaciones económicas continentales que agudiza la desigualdad y la reedición de viejos y nuevos conflictos. La necesidad de terminación de las guerras liquidando adversarios o imponiendo la paz armada son el preludio de mayor desigualdad y el anuncio de nuevas guerras.

La Declaración Universal de los Derechos Humanos a diferencia de otras concertaciones sobre este tema, es el acuerdo suscrito por la mayoría de países y cuya influencia se ha plasmado en sus constituciones nacionales. En dicha Declaración se considera a todos los seres humanos como iguales en "dignidad y derechos", aun cuando hay una cómplice omisión a la desigualdad en el usufructo de recursos, capacidades y potencialidades. Iguales en las diferencias es una expresión de un statuo quo conservador, dado que la igualdad de derechos oculta las carencias, necesidades y problemáticas de los subalternos. La igualdad entre los pobres y sin voz, frente a la igualdad entre ricos con poder, es una separación artificial y distorsionadora de sectores sociales que son interdependientes. Esta disociación liberal arguye falsamente que cada sector social es responsable de su situación y destino.

Todos iguales ante la ley, plasmado en el art. 7 de la Declaración Universal de los Derechos Humanos (DUDH), ignora las facultades negadas a los excluidos a lo largo de los tiempos, así como se desconoce y violenta la pluralidad social, cultural e histórica de los pueblos que han creado insondables abismos que requieren ser compensados socialmente, porque perdurn sus consecuencias. Asimismo, la igualdad establecida $y$ delimitada por diversas normas de la propia DuDH (Bayefsky, 1990), no son delimitaciones políticas derivadas de la situación y condición de los excluidos y subalternos de las sociedades del mundo, sino porla hegemonía política de la posguerra. La adopción de prácticas igualitarias como modo para paliar las desigualdades, no son consistentes, pues la desigualdad se acrecienta por las distintas condiciones y vulnerabilidad social, política y económica de un sistema inequitativo que se sustenta en la explotación del trabajo y la apropiación de las riquezas de los pueblos y sociedades. La igualdad entre desiguales se plasma en los Tratados de Libre Comercio (TLC) entre naciones con distinto desarrollo relativo, pero con igual normativa. La desigualdad histórica determina que los subalternos, en su diversidad, no requieran idénticos sino distintos derechos que pueda compensar las diferencias de un sistema inequitativo.

En las circunstancias de la Declaración Universal de los Derechos Humanos, la paz y los enunciados por la igualdad eran anhelos de las naciones del mundo, sin embargo, el triunfo aliado también constituyó la universalidad del poder mundial, así como, la imposición de un estilo de desarrollo y una forma de organización de la 
economía y sociedad. Se reconocía igualdad en un statuo quo determinado en un universo delimitado, así en nombre de la universalidad se segrega a millones de personas (Tarracena, 2005) a su pertenencia racial, cultural, religiosa, política, etc., distinta a la instaurada con la colonialidad del poder. En la formalización de la Declaración Universal, la igualdad está fundada en la colonialidad del poder global establecido después de la II GM como una adecuación de la segregación a la nueva hegemonía mundial. La desigualdad está arraigada a la totalidad histórica, política, económica e ideológica, más allá de sus formalizaciones jurídicas y de indicadores cuantitativos.

La universalidad de ningún modo implica homogenización, lo humano y lo físico natural es diverso y plural. El universalismo de la cultura superior, de la modernidad tecnológica capitalista, del estilo de vida norteamericano o europeo, o la homogeneidad metodológica cuantitativa de indicadores $y$ datos se tiñe de un igualitarismo que encubre un totalitarismo $y$ absolutismo contra los otros. Esa universalidad es la del poder global, del particularismo de la colonialidad del poder (Serres, 2005), de la intolerancia e ignorancia de la barbarie (Morín, 2006).

En el presente, la polaridad en las sociedades se ha acrecentado y es América Latina el espacio de la mayor brecha social del planeta, lo cual no solo muestra la infructuosa acción de los organismos internacionales por el derecho a la igualdad, luego de 60 años de actividad, es también la evidencia estructural de las relaciones desiguales de un sistema que se nutre de esta (Sen y Kliksberg, 2008). Los derechos civiles, económicos, políticos, las remuneraciones no discriminatorias, el acceso a la cultura y educación, la protección a la vida, a los niños, mujeres, discapacitados o contra la tortura, etc., siguen siendo anhelos de muchas sociedades, a pesar de las normas nacionales y la suscripción de acuerdos internacionales ${ }^{10}$.

10 Estados Unidos de Norte América es quizás el único país del mundo que violenta todos los acuerdos internacionales, tal es caso que las prohibiciones a la tortura o al encarcelamiento sin juicio, este país los aplica impunemente en Guantánamo, así como violenta unilateralmente cualquier acuerdo
Las reivindicaciones de derechos formalizados no son igualitarias, son particulares en razón de las condiciones y de la situación de la conciencia y los conocimientos conquistados por sus protagonistas. La igualdad no es igualitaria, válida ni pertinente, cuando es ajena a sus protagonistas. Los derechos alcanzados no son automáticos, requieren de la defensa activa de sus actores o por la acción institucional estatal que represente el interés ciudadano. La formalización de derechos sin participación social que los defienda y sin un Estado con capacidad de hacer cumplir y adecuar las pautas legales y constitucionales, son limitaciones que vulneran los derechos conquistados y provocan mayor discriminación. La viabilidad formal y estatal en las relaciones sociales entre desiguales, en concertación, conflicto o antagonismo, determinarán nuevas formas de consenso o dominio.

El igualitarismo en la desigualdad, no es afín ni complementario a la libertad, democracia, la justicia ni el bienestar, por el contrario, es el complemento a la estandarización y mecanización de las relaciones sociales funcionales al poder y al capital. El igualitarismo en la desigualdad es la validación ideológica liberal e individualista de la dominación occidental en una época de monopolio de la hegemonía política, militar y económica en el mundo.

\section{EL SUFRAGIO UNIVERSAL ¿IGUALDAD?}

Cabe anotar que la dignidad y los derechos igualitarios de la Declaración Universal de los Derechos Humanos sobre cualquier tipo de discriminación, intolerancia e injusticia, se desconoce u oculta las condiciones sociales, la significación simbólica y la disponibilidad de recursos de los individuos, grupos, clases y sociedades (Garretón, 2012). En esse sentido, el sufragio universal no es un ejemplo de igualdad. La votación es un acto formal e instrumental que de ningún modo supone similares condiciones sociales y políticas que garanticen la voluntad del elector (Huaylupo, 2016).

con otros países, como es el caso actual del TLCAN (Flores y Hernández, 2004; Romero, 2006). 
Desde la individualización del voto se despersonificaba la totalidad social, el interés general y lo común a todos. Así, el sufragio universal convierte a la democracia, la justicia y la igualdad en un simple acto técnico, instrumental e individualista. Las expresiones colectivas quedan reducidas paradójicamente a expresiones individualizadas, indiferenciadas y aisladas ${ }^{11}$. La participación política de la ciudadanía no está dada por la actuación como personas electoras, sino como participes activos, con otros, a un proyecto común gestionado colectivamente (Arendt, 1997), tampoco es reducible a lo establecido por la normatividad institucional porque ello no define ni delimita el pensamiento $y$ la voluntad colectiva por un destino compartido (Córdova, 2015), menos aun cuando es formalizado por otros en el poder.

Las sociedades modernas han consagrado la individualidad como un prejuicio de herencia griega (Jaeger, 2001; Huntington, 1997), pero también y de la colonialidad del poder de un sistema que se ha legalizado y legitimado jurídica e ideológicamente la apropiación privada capitalista e invisibilizado la generación colectiva de la riqueza.

El voto se ha legitimado socialmente como un acto de valoración y enjuiciamiento colectivo, aun cuando solo es la adición de ponderaciones individualizadas. En los procesos electorales, las igualdades cuantitativas no reproducen las desigualdades del contexto ni representan la heterogeneidad de condiciones, criterios, necesidades o anhelos colectivos de la población electora. Lo colectivo, lo público o lo común no se define con la cantidad de votos, es más trascendente y complejo que cualquier conjunto de votos aislados, a la vez que los procesos instrumentales de votación se encuentran regulados por normas y están condicionados tanto por la desigualdad imperante, como por las prácticas demagógicas, mercantiles, clientelares y mediáticas. La igualdad y la libertad

11 La creencia generalizada por la teoría de los conjuntos de que la suma de las partes es igual al todo, es una visión que podrá ser válida en el lenguaje de la formalización matemática, sin embargo, no lo es en las teorías ni en el lenguaje de la ciencia fáctica (Huaylupo, 2008, 2014c y 2016). de las personas en los procesos electorales son aparentes, no solo porque en sociedades masificadas y complejas se desconoce la representatividad de los candidatos, porque se mercantiliza el voto, por el chantaje electoral o por difundir terror y engaño en los electores, entre otras formas de condicionamiento del voto, pero también habría que mencionar que la ciudadanía carece de la facultad para definir, razonar, participar y decidir en la elección de los candidatos, en la decisión de las políticas públicas, así como en la evaluación y fiscalización de la actuación de los elegidos y de los entes públicos. De este modo, el electorado se convierte en un medio que formaliza el poder privado en la regularidad sistémica de la desigualdad e inequidad capitalista.

Los actos electorales modernos no guardan mayor diferencia con otros ocurridos en el pasado, dado que la competencia electoral no fue una creación de la Declaración de los Derechos Humanos, sino que ya existían en la Grecia antigua, cuando los derechos igualitarios solo eran para esclavistas, para los pocos que detentaban el poder omnímodo, mientras que los muchos esclavos, solo tenían el deber de trabajar y obedecer. Asimismo, en la Inglaterra de fines del siglo XIX, las elecciones eran definidas por el $17 \%$ de las personas con derecho a votar (Córdova, 2015). Las elecciones no son expresiones de la democracia, pues en sociedades sin derechos ha existido, asimismo, el incremento del abstencionismo no es una amenaza para la sostenibilidad democrática como creen algunos (Mizrahi, 2015).

El sufragio universal no garantiza la universalidad de votantes, como se evidencia ante el creciente abstencionismo en los procesos electorales de muchas naciones, lo cual pone de manifiesto la decepción o la indiferencia social en los procesos electorales que no los representan, ni se define el bienestar común y público. En Chile, solo participó el $57 \%$ de la población electoral que eligió a Michelle Bachelet, en el 2013; Eslovenia, Mali, Portugal, Lesoto, Lituania, Colombia, Bulgaria y Suiza son países que tienen más del 50\% del abstencionismo electoral, también es alto en aquellos que tienen como obligatorio el voto, como México, Grecia y 
Paraguay, cuyo abstencionismo supera el 30\%; entre los que superan el 20\% se encuentran República Dominicana, Turquía y Panamá, y entre los mayores al 10\% se encuentan Brasil, Argentina $y$ Ecuador. De modo que ni la obligatoriedad del voto con las multas y las limitaciones del ejercicio ciudadano, posibilitan el ejercicio del derecho al voto de las poblaciones que se abstienen (Mizrahi, 2015; Red de Conocimientos Electorales-RCE, 2011).

En tal sentido, es posible afirmar que las elecciones son procesos privados que no representan la pluralidad de los electores ni articulan un pensamiento y acción que sea común a todos en una sociedad integrada e interdependiente. Así, la degradación y liquidación de la representación colectiva son consecuencias de la privatización de la función e institucionalidad pública, pero también de lo privativo de los procesos electorales.

Las formas instrumentales e individualistas privadas de ningún modo pueden ser el sustento de actos sociales y políticos de una sociedad. En el acto de votar no se considera cómo se hace, ni en qué condiciones o circunstancias, así como tampoco importa a quién se elige ni la representación social de las personas elegidas, a la vez que se ignora la voluntad, las necesidades $y$ los anhelos de las personas electoras de la colectividad organizada, para interesarse exclusivamente en la cantidad de votos obtenidos. Es decir, el voto individualizado y aislado no es la materialización del sentimiento, la conciencia, el interés ni el anhelo de lo que es común a la colectividad ciudadana.

A la agregación mecánica de votos coincidentes de la heterogeneidad social se le ha asignado erróneamente la representación de una voluntad colectiva en los procesos electorales, aunque en dichos actos no se dirime ni se reduce la voluntad colectiva (Huaylupo, 2014a y 2014b ). El sufragio es un símbolo de la igualdad, pero no es la manifestación de la soberanía del pueblo ni de las personas subalternas, como tampoco es la expresión de equidad, justicia, libertad o de la democracia. El orden social capitalista y liberal tienen en el individualismo posesivo su fundamento, el acto de sufragar y la libertad vistos como cualidades individuales, oculta, ignora y simplifica los derechos políticos de las colectividades (Arendt, 2004). La colectividad, el bien común o lo público y lo nacional son ajenos a los procesos electorales y sus determinaciones jurídicas (Huaylupo, 2016).

$\mathrm{El}$ derecho individual tiene preeminencia sobre el derecho colectivo, aun cuando es la colectividad quien otorga significación e identidad particular a los individuos que no son indiferenciados ni las leyes son privativas. La vida en sociedad implica compartir un destino común, lo privado es la separación de lo común y público por conveniencia ante los privilegios y facultades que permite imponer, dominar y supeditar a las colectividades, como se ha validado en un inequitativo sistema privativo en la economía, política y la normatividad jurídica, que las elecciones ratifican $y$ consolidan.

\section{LA IGUALDAD ECONÓMICA ¿EL MERCADO?}

Los explotados que crean riqueza y los excluidos del trabajo remunerado son los productores $y$ consumidores de mercancías del mundo capitalista. Los que permiten la producción, la reproducción y la ampliación de la rentabilidad del capital, son los extraños del bienestar, del acceso a los recursos para la vida $y$ sin un futuro para su realización personal y social. El régimen económico capitalista surgió de la desigualdad y la reproduce en una escala superior a la acumulación privada del bienestar.

En el capitalismo, la desigualdad económica es intrínseca a su desenvolvimiento cotidiano, sin embargo, asume consideraciones ideológicas igualitarias. La apariencia igualitaria entre los actores del proceso de trabajo, esta ejemplificada en una relación mercantil, como la libertad de compra y de venta de la fuerza de trabajo, así como se iguala el derecho a pago del trabajo (salario) con el derecho a la apropiación del excedente generado con el trabajo (plusvalor). Esto es, igualdades jurídicas que se nutren de las desigualdades reales en la interrelación de la reproducción social y del poder. Esas igualdades no son equivalentes: los salarios con la plusvalía, como tampoco son comparables las necesidades de vender el trabajo para la subsistencia de los proletarios con la acumulación para la reproducción ampliada 
del capital. La igualdad supone desigualdad en un contexto que la valida, la reproduce y la legitima. No existe igualdad ni desigualdad libre de la determinación contextual, así como es aparente y formal la igualdad en la desigualdad del sistema capitalista prevaleciente.

La libertad y la igualdad son categorías destacadas en el devenir económico porque se les atribuye reciprocidad y complementariedad, sin embargo, no existe libertad ni igualdad cuando son unos quienes la definen para los otros, así como tampoco lo habrá cuando se imponen idénticos medios, recursos y servicios a poblaciones plurales $y$ diversas. En la economía capitalista se asume que los actores de la interrelación económica son iguales cuando los oferentes y demandantes concurren en un espacio social para el intercambio (DineroMercancía-Dinero). De este modo, productores $y$ comerciantes ofrecen sus bienes a quienes los demandan por dinero, esta igualdad es aparente, dada la desigualdad y equilibrio entre los oferentes y los demandantes.

La desigualdad se manifiesta en la capacidad unilateral de propietarios en la conversión en capital de los valores plasmados en las mercancías y los captados de los compradores, así como, por la disposición y condicionamiento en la calidad de vida de los consumidores y trabajadores. La libertad ponderada en la economía es la del propietario del capital que reproduce desigualdad en el proceso productivo. Una libertad para unos en un universo de supeditación y dominación, es semejante a los hombres libres en el contexto de la sociedad esclavista.

Es sugerente el planteamiento de Amartya Sen al concebir el desarrollo como expansión de las libertades fundamentales (Sen, 2000), no obstante, su postulación está referida a un contexto que ha validado la igualdad de derechos entre las personas, a la vez es un reconocimiento que la economía crece y expande en ámbitos políticos con igualdad formal con desigualdad social. La valorización ampliada del capital requiere de libertad para la inversión, la explotación del trabajo y la expansión del capital, pero para consumirla o destruirla productivamente. Una libertad que antagoniza con los trabajadores cautivos durante las jornadas laborales. La igualdad formal en la desigualdad fáctica, esta desposeída de la facultad para regular, equilibrar o resolver el antagonismo sistémico, tal y como la desigualdad profundiza la desigualdad la liquidación o debilitamiento de la actuación reguladora estatal en el devenir social y económico.

El mercado como la interrelación entre productores y consumidores, así como, medio de conversión y transferencia de valores, son manifestaciones necesarias para los actores con distintas capacidades $y$ recursos para su sostenibilidad que reproduce desigualdad en las relaciones capitalistas, las cuales no son equitativas ni están libres de las determinaciones sociales y políticas imperantes.

Los consumidores acceden a los bienes y servicios a condición de poder pagarlos y satisfacer sus necesidades y según los patrones culturales, como los productores y comerciantes podrán ofertar en razón de sus capacidades productivas, de las condiciones mercantiles, tributarias, de las necesidades $y$ demandas existentes, así como podrán convertir en capital el plusvalor y las mercancías. Así, se reproduce y amplía la desigualdad, mientras unos satisfacen necesidades para la vida y como clase subalterna, los propietarios del capital se apropian de los valores generados por el trabajo $y$ de los recursos de los consumidores por la inequidad del intercambio mercantil, para crear más capital para la explotación y la riqueza privada. El hambre y la miseria del mundo es una evidencia de la desigualdad creada por la injusticia distributiva de los excedentes generados mundialmente.

Se dice que en el mercado laboral existe igualdad entre los trabajadores $y$ empresarios porque se necesitan y tienen la libertad de comprar y dar trabajo, mientras que otros venden su trabajo para ser empleado productivamente, pero esa necesidad recíproca no supone igualdad. La supuesta libertad de concurrencia al mercado es relativa, pues es una condición obligada para la producción y la reproducción de los protagonistas, como también del sistema. Sin embargo, la concentración y la centralización del capital, la producción y la tecnología, confinan al hambre y a la miseria 
a cada vez mayores poblaciones excluidas del trabajo, así como son absorbidas o liquidadas las actividades productivas para la subsistencia en el mundo.

Asimismo, el mercado no es la concreción económica individual de la libertad de elección para los consumidores ni los productores, qué producir, cómo y dónde hacerlo, a qué precios y cantidades o las formas de comercializar las mercancías, se encuentran determinadas por las condiciones sociales, históricas y culturales. La elección mercantil del consumo y la producción en la sociedad capitalista es en apariencia, aunque es social. Los gustos $y$ las preferencias están condicionadas colectiva, cultural e históricamente. La similitud de las necesidades de las personas o sociedades, se satisfacen de modo particular, no es individual ni autosuficiente. En el presente, se homogeniza el consumo, no en razón de idénticas necesidades, sino por la mundialización de la producción y comercialización de los consorcios mundiales. La globalización homogeniza el consumo en razón de decisiones y condiciones de rentabilidad privada, no en función de las determinaciones sociales, culturales, ecológicas o ambientales, como manifestación de poderes ajenos de las poblaciones y sociedades del mundo.

El mercado es la concreción de la desigualdad y de la impersonalidad en las relaciones mercantiles, no crea riqueza, se apropia, transfiere $y$ transmuta de valores existentes, siendo una condición de interdependencia entre productores y consumidores, que no es característico ni exclusivo de las relaciones económicas contemporáneas. Destacar al mercado como expresión esencial de la economía en la fantasía liberal, es un absurdo, los mercados han acompañado la historia de la división del trabajo y de la vida en sociedad, pero no han modelado las relaciones sociales, por el contrario son las relaciones sociales $y$ productivas las que han condicionado el funcionamiento de los mercados. La aparente igualdad de acceso al mercado en el capitalismo, oculta el contexto de la desigualdad, del ciclo de la reproducción ampliada y del sistema social y político prevaleciente.
La creciente desigualdad es diversa en su forma y contenido, sin embargo, es la económica a la que se le asigna la mayor importancia, dado que se cree que la posesión o disponibilidad de dinero es el factor diferencial en la organización social, lo cual pone evidencia de la significación del dinero para la circulación y la acumulación de capital en la mercantilización de las relaciones en la sociedad capitalista. La idea de igualdad económica supone la posibilidad individual de igualar la posesión de recursos para satisfacer necesidades, crear calidad de vida $y$ bienestar, e incluso paradojicamente se asume, que el incremento de la capacidad adquisitiva de la población será fuente para el crecimiento y la expansión económica empresarial y nacional por la apropiación privada de la riqueza social. El economicismo como forma privilegiada para interpretar la situación económica y la pobreza, por el contrario, distorsina la comprensión de las realidades. Asi, en la Gran Depresión de 1929-1933 (Galbraith, 2009), quizás la más drástica conocida por estados Unidos y el mundo, Franklin Delano Roousevelt mostraba con el New Deal, la supeditación de la economía al trabajo, a la voluntad de las mayorías y al compromiso social del Estado.

Desde esta posición, la totalidad social carece de estatuto propio para todo ser reducido a la sumatoria de individuos, luego la pobreza o la desocupación, son productos del pensamiento $y$ acción de los pobres $y$ desempleados, sin determinación histórica, estructural, exclusión $y$ dominio social o de desigualdad clasista. El individualismo como determinación ideológica pragmática, se trasmuta en individualismo metodológico, a una posición epistemológica que simplifica y reduce lo complejo a determinaciones absolutas $y$ de causalidad única. La pobreza de los que crean riqueza, no puede ser comprendida desde la contrarrevolución teórica, ideológica y epistemológica individualista (Pereyra, 2010).

La ponderación de lo económico como factor generador de riqueza adquiere una dimensión de vital importancia en la simplificación individualista, al considerar que la precariedad de recursos económicos es la causa de la desigualdad. Luego, falazmente se asume 
que la mayor riqueza en la sociedad permitirá resolver la problemática de la desigualdad social. Al respecto y de manera similar, la CEPAL asume que la injusticia distributiva está implícita en la desigualdad económica, por ello en sus estudios lo considera vital para el crecimiento y expansión del sistema y también para la igualdad. De este modo, el crecimiento y la expansión económica se convierten en las acciones prioritarias, que siendo básicamente actividades fundamentalmente privadas, son consideradas como los artífices contra la desigualdad. Este argumento economicista sirve a los empresarios para afirmar ser los únicos creadores de riqueza, para lo cual exigen incentivos, subsidios, concesiones y patrocinio a sus inversiones, las cuales son apoyadas por gobiernos y parlamentos liberales.

Así, desde algunos Estados se promueve riqueza privada y desigualdad generalizada, dado que, son prácticas acompañadas con restricción y privatización de las políticas públicas (Huaylupo, 1999). Los propietarios del capital se apropian de la riqueza generada por los trabajadores en la producción, así como se apropian de los recursos de los consumidores de mercancías, empobrecen a quienes los enriquecen: trabajadores, consumidores y Estado. La tendencia a la mayor capitalización privada corresponde con la mayor inversión y la mayor desigualdad en el mundo.

La igualdad es apreciada desde el utilitarismo economicista como un medio para el crecimiento, porque se cree que la identidad igualitaria entre los trabajadores proporciona mayores capacidades y las optimiza en el logro de mayor productividad y competitividad económica (CEPAL, 2014a) y constituye el "... principio rectificador a lo largo del ciclo de vida" (CEPAL, 2014a: 51). Es decir, el ente cepalino cree que la igualdad permite alcanzar mejores niveles de vida, satisfacción, recursos y bienestar para la sociedad, lo cual es un planteamiento circular.

La desigualdad en la sociedad capitalista se encubre en aparentes $y$ parciales igualdades, como necesidad ideológica para reproducirse eliminando toda identidad propia en la subalteridad y toda resistencia a procesos que no les serían ajenos. La subordinación de los individuos y colectividades es la estandarización de los valores y prácticas que les son ajenas, de este modo los "buenos" esfuerzos y discursos liberales por la igualdad, son ambiguos caminos de la colonialidad del saber, del hacer $y$ del poder en las relaciones sociales desiguales.

La pobreza y el desempleo son problemáticas globales del presente que desintegran y polarizan la sociedad, a la vez que ponen en evidencia la vulnerabilidad de las políticas públicas imposibilitadas de compensar los desequilibrios generados por las relaciones inequitativas. Asimismo, la disminución de la capacidad adquisitiva por la precariedad del salario de las poblaciones incide en la reproducción ampliada del capital, deteriora la capacidad organizativa de la población trabajadora, así como, afecta la condición y la calidad de vida de las mayorías. De este modo, se polariza la sociedad y se potencia la violencia en las relaciones sociales y la actuación estatal, en un proceso regresivo contra la democracia y la libertad.

En el presente son muchos quienes coinciden en caracterizar a los trabajadores como los nuevos esclavos del siglo XxI (Fernández, 2011; Silva, 2012; Archidiócesis de Madrid, 2017; Periódico Público, 2015; Carrasco, 2015), en tal sentido, Aristóteles afirmaba que los esclavos eran útiles $y$ necesarios para el poder y la sociedad, sin poder dedicarse a pensar ni actuar sobre asuntos de gobierno, como tampoco capacitados para forjarse una vida propia e independiente, sin embargo, esa condición no era por decisiones individuales, sino por factores estructurales de la organicidad del poder esclavista. Esta caracterización contemporánea de los trabajadores constituye una auténtica regresión social en la globalización contemporánea.

\section{LA POLÍTICA PÚBLICA Y LA IGUALDAD}

La acción pública estatal es la manifestación de su compromiso y responsabilidad asumida en representación de la heterogeneidad social y la pluralidad de intereses en la sociedad. Este proceso es posible en un contexto que ha construido lo público, la ciudadanía y la igualdad jurídica en la sociedad civil, lo cual también es la constitución de lo político en la sociedad capitalista. De manera específica, 
la política pública es la intervención estatal originada en el ámbito de la heterogeneidad, el conflicto y la concertación social entre desiguales: la sociedad civil. Así, la política pública es el mandato social que debe ser formalizado, diseñado y ejecutado por el Estado, así como, evaluado y fiscalizado por la organicidad de la pluralidad social.

El Estado Social, el Estado Benefactor o Estado Nacional son expresiones y énfasis distintos de un ente que representa a la sociedad con sus clases y sus desigualdades. El representar el interés común de la sociedad capitalista, no es ninguna concesión a los sectores subalternos, es una necesidad en una sociedad donde todos son interdependientes. El explotar y pauperizar sin límites a trabajadores y los excluidos, no es una alternativa para la reproducción de esta forma de organización social y económica, como tampoco lo es la competitividad destructiva entre propietarios. El Estado es una forma organizativa de la sociedad, que no es neutra, el fundamento de su quehacer es reproducir la sociedad capitalista y sus clases, donde todos están representados, pero desigualmente. El capitalismo es un sistema que ha integrado a la sociedad en su conjunto, construyendo una totalidad interdependiente e inextricable, donde ningún actor social es autónomo o libre de las determinaciones de los otros.

En tal sentido, no es posible que el Estado Social pueda ni es su propósito eliminar las desigualdades de un sistema que debe garantizar su reproducción y su propia existencia como Estado clasista. La necesidad de garantizar la condición de vida de las clases subalternas es una condición para la reproducción económica $y$ política del sistema $y$ del poder, el cual es distinto a otras formaciones sociales del pasado. El conflicto entre propietarios y con las clases subalternas no es una tarea que pueda ser dirimida por sus protagonistas, es el Estado Social el mediador del conflicto y donde su actuación es el factor de estabilización y de hegemonía.

Una función del Estado de Bienestar es hacer política pública y limitar las acciones privadas que atenten contra los otros, a la vez que crea un aparato institucional para garantizar las acciones requeridas para la reproducción en desigualdad de los sectores vulnerables de la sociedad. Esto es, el ámbito de la política estatal está definido $y$ delimitado por las relaciones y la conflictividad entre los protagonistas sociales (Chantal, 2011). De este modo, la mediación política es una condición estatal para la continuidad sistémica en una sociedad desigual y contradictoria. En tal sentido, la política pública es una intervención estatal en razón de las desigualdades, antagonismos y anhelos ciudadanos en espacios específicos, no para eliminar la desigualdad ni sus contradicciones, porque trasciende a su función como forma organizativa de la sociedad, sino para paliarlos, diferirlos, negociarlos o subsumirlos ${ }^{12}$.

Es por estas características que es el Estado quien se convierte en un actor importante en los procesos de regulación de las relaciones sociales en la desigualdad de la sociedad $y$ a quien se le atribuye la responsabilidad en el crecimiento y la expansión del capital global, así como, la estabilidad social y la equidad en la sociedad.

En la desigualdad, el equilibrio es básicamente inestable y crítico porque las relaciones sociales no podrán constituirse del mismo modo, como el poder tampoco podrá dominar o hegemonizar como en el pasado. La relativización de la organicidad de los subalternos en la agudización de la desigualdad, explotación y liquidación del Estado Social no supone pasividad social ni estabilidad política. En crisis el adversario en la otredad y la desigualdad

12 Es una regularidad en las interpretaciones sobre la política pública concebida como una facultad autónoma de todo Estado para concebir, diseñar y ejecutar intervenciones en la sociedad. De este modo, las instituciones nacionales e internacionales proponen políticas públicas, según las experiencias en otros contextos o por la fundamentación de sus argumentaciones. Así, la política pública queda reducida a la concepción e interés de quienes ejercen el poder estatal, donde la pluralidad social no se encuentra representada, o solo está un sector social considerado como el más importante por su organicidad e influencia. No obstante, la política pública no es una facultad de todo Estado, esta se construye en la sociedad civil y la acción pública del Estado es una consecuencia de la problemática, perspectivas y anhelos comunes de la ciudadanía en un específico espacio-tiempo social. 
es el enemigo en guerra. El equilibrio es catastrófico, a decir de Antonio Gramsci (BuciGlucksmann, 1979), no por la imposibilidad de gobernar bajo la dominación clasista, sino porque la globalización relativiza el poder estatal o su actuación pública para las condiciones nacionales, ante la imposibilidad política de limitar las tendencias e inestabilidad económica mundial. La desigualdad en las relaciones internacionales es evidente en la inestabilidad del acontecer político internacional del presente.

En el ámbito nacional costarricense las consecuencias del liberalismo de la década del 80 del siglo pasado, que no ha desaparecido, debilitaron la institucionalidad pública, así como mellaron la eficacia de la función estatal, a la vez que aumentaron la explotación y la precarización del trabajo. La desocupación, la pérdida de organicidad y la mayor desigualdad de las poblaciones trabajadoras fueron también sus efectos. Las contradicciones y antagonismos de la sociedad tienen en el ámbito estatal e institucional, el espacio para dirimir desigualmente poderes $y$ acciones contra los derechos humanos y ciudadanos. La regresión social en la actualidad no es una tendencia posible, es una realidad en Brasil, Argentina, Costa Rica, etc.

La liquidación del Estado Social en América Latina ha sido $y$ es un proyecto liberal, porque lo necesita para la acumulación y el crecimiento del capital, así como para proteger y condicionar la expansión de sus intereses. La desregulación y el quebranto de la institucionalidad estatal están relacionadas con la privatización de la política, la desigualdad, la ingobernabilidad y la ilegitimidad estatal.

El debilitamiento o liquidación de la política pública para privilegiar a los propietarios privados, es el antecedente crítico de la pérdida de la capacidad mediadora y la atenuación de las iniquidades sociales por parte del quehacer estatal. La precarización o la desaparición de la política pública afecta directamente la suficiencia y la vida de los sectores vulnerables. La inestabilidad es la convergencia de las contradicciones clasistas y de la ingobernabilidad estatal (Dworkin, 2003), razón por la cual los entes internacionales critican, presionan y recomiendan acciones específicas en determinados espacios e indicadores, sin la participación ciudadana (CEPAL, 2015; Medina, Becerra y Castaño, 2014; Díaz y Isuani, 2015). De este modo, la política pública se convierte en una aplicación técnica donde la ciudadanía carece de libertad para proponer, definir $y$ decidir las acciones estatales según sus necesidades $y$ anhelos sociales. Esas acciones que se sugieren, financian y ejecutan, están lejos de ser propuestas democráticas, por el contrario, son auténticos proyectos totalitarios (Bauman, 2014; Arendt, 2015).

\section{REFERENCIAS}

Arendt, H. (1997) ¿Qué es la Política? Barcelona: Editorial Paidós.

Arendt, H.(2004). Sobre la revolución. España: Alianza editorial Versión española de Pedro Bravo.

Arendt, H. (2015). La promesa de la política. Argentina: Editorial Paidós.

Archidiócesis de Madrid. (2017). Los nuevos esclavos del siglo XXI. Recuperado de https:// archimadrid.org/index.php/oficina-deinformación/noticias-mundo/item89813los-nuevosesclavos-del-siglo-xxi

Banco Interamericano de Desarrollo. (1999). IPES 1998-1999: América Latina frente a la desigualdad. Washington: Informe de Progreso Económico y Social (IPES).

Banco Interamericano de Desarrollo. (2008). Calidad de vida más allá de los hechos. México, Desarrollo de las Américas: BID y Editorial Fondo de Cultura Económica.

Banco Mundial. (2016). Pobreza y desigualdad de América Latina en cinco tweets. Recuperado de www.bancomundial. org/es/news/feature/2016/05/16pobre$z a-y$-desigualdad-de-america-latina-en-cinco-tweets

Bauman, Z. (2014). Libertad y seguridad: un caso de Hassliebe. En Z. Bauman, y A. Dessal, El retorno del péndulo. España: Editorial Fondo de Cultura Económica.

Bayefsky, A. (1990). The Principle of Equality or Non-Discrimination in International Law. Human Rights Law Journal, 11, (1-2), 1-34. 
Bobbio, N. (2009). Teoría General de la Política. España: Editorial Trotta.

Buci-Glucksmann, C. (1979). Gramsci y el Estado. México: Siglo Veintiuno editores.

Comisión Económica para América Latina y el Caribe (CEPAL). (2012). Eslabones de la desigualdad. Heterogeneidad estructural, empleo y protección social. Santiago de Chile: CEPAL, Naciones Unidas.

Comisión Económica para América Latina y el Caribe (CEPAL). (2014a). La hora de la igualdad. Brechas por cerrar, caminos por abrir. Santiago de Chile: CEPAL, Naciones Unidas.

Comisión Económica para América Latina y el Caribe (CEPAL). (2014b). Cambio estructural para la igualdad. Santiago de Chile: CEPAL, Naciones Unidas.

Comisión Económica para América Latina y el Caribe (CEPAL). (2015). Pactos para la igualdad. Santiago de Chile: CEPAL, Naciones Unidas.

Comisión Económica para América Latina y el Caribe (CEPAL). (2016). Horizontes 2030. La igualdad en el centro del desarrollo sostenible. Santiago de Chile: Paidós.

Chantal, M. (2011). En torno a lo político. México: Editorial Fondo de Cultura Económica.

Carrasco, E. (2015). Los (nuevos) esclavos del siglo XXI. Economía, justicia social. Recuperado de enriquecarrasco.com/losnuevos-esclavos-del siglo-xxi

Cohen, G. (1996). ¿Igualdad de qué? Sobre el bienestar, los bienes y las capacidades. En A. Sen, y M. Nussbaum (Comp.). La calidad de vida (pp.27-53). México: Editorial Fondo de Cultura Económica.

Comte, A. (2002). Discurso sobre el espíritu positivo. Barcelona: Ediciones Folio.

Córdova, D. (2015). Repensar la igualdad democrática: Isonomía, isegoría, isotimia. Revista Colección, (25), 11-39.

Díaz, C. y Isuani, F. (Comp.) (2015). Políticas públicas en Estados subnacionales. Argentina. Ciudad Autónoma de Buenos Aires: Sociedad Argentina de Análisis Político (SAAP).
Dworkin, R. (2003). Virtud soberana. La teoría y la práctica de la igualdad. Barcelona: Editorial Paidós.

Dworkin, R. (2012). Los derechos en serio. Barcelona: Editorial Ariel.

Fernández, C. (2011). Los nuevos esclavos. Recuperado de www.haine.org/espana/ nuevos_esclavos.htm

Ferranti, de D., Perry, G., Ferreyra, F. y Walton, M. (2005). Desigualdad en América Latina ¿Rompiendo con la historia? Bogotá: Banco Mundial y Ed. Alfaomega Colombiana S.A.

Flores, M. y Hernández, G. (ed)(2004). TLC con Estados Unidos. Costa Rica: Instituto de Investigaciones Sociales de la Universidad de Costa Rica.

Friedman, M. y Friedman, R. (1980). Libertad de elegir. Barcelona: Editorial Grijalbo.

Galbraith, J. (2009). The Great Crash 1929. Boston: Mariner Book.

Garreton, M. (2012). Igualdad: dimensiones, luchas y pactos sociales. En R. Casas y H. Carton (Comp.). Democracia, conocimiento y cultura (pp. 145-168). México: Instituto de Investigaciones Sociales, Universidad Nacional Autónoma de México y Bonilla Artigas Editores.

Gouldner, A. (1979). El antiminotauro. El mito de una sociología no valorativa. $L a$ sociología actual: renovación y crítica. Madrid: Editorial Alianza.

Habermas, J. (1984). Ciencia y técnica como $<$ ideología>. Madrid: Editorial Tecnos.

Hobsbawm, E. (1999). Historia del siglo XX. Buenos Aires: Editorial Crítica Grijalbo Mondadori.

Huaylupo, J. (1999). Las políticas públicas en un contexto de privatización de la práctica social del Estado. Revista Mexicana de Sociología.61 (4), 55-72.

Huaylupo, J. (2008). Relatividad y significación de los datos. Cinta de Moebio. Revista de Epistemología de Ciencias Sociales (32),127-152. Recuperado de www.moebio.uchile.cl/32/huaylupo.html

Huaylupo, J. (21 febrero de 2014a). La democracia ante el riesgo tecnocrático del 
proceso electoral. Diario virtual El País. Recuperado de http://www.elpais.cr/frontend/noticia_detalle/3/90199

Huaylupo, J. (20 marzo de 2014b). ¿Crónica de un fraude anunciado? Diario virtual El País. Recuperado de http://www.elpais.cr/ frontend/noticia_detalle/3/90890

Huaylupo, J. (2014c). Uso y abuso de la matematización delas realidades. Opinión. Semanario Universidad. Edición nro. 2044. San José, Costa Rica. Recuperado de http://www.semanariouniversidad.ucr. ac.cr/component/content/article/4551-opinion/13333-uso-y-abuso-de-la-matematizacion-de-las-realizadades-.html

Huaylupo, J. (02 de abril de 2016). La democracia: Más allá de lo normativo, electoral y técnico. Diario Digital El País. Opinión. Recuperado de http://www. elpais.cr/2016/04/02/la-democracia-masalla-de-lo-normativo-electoral-y-tecnico/

Huntington, S. (1997). Occidente único no universal. Estudios de Política Exterior (55), 141-160.

Jaeger, W. (2001). Paideia: los ideales de la cultura griega. México: Editorial Fondo de Cultura Económica.

Kliksberg, B. (2002). América Latina: Una región en riesgo. Pobreza e inequidad. Revista de Ciencias Sociales, VIII (1), 9-22.

Kliksberg, B. (2010). El secreto para combatir la desigualdad es crear un para todos: Kliksberg en CNN. Recuperado de www. aristeguinoticias.com/2010/entrevistas/ el-secreto-es-crear-un-para-todos-kliksberg-en-cnn/

Kliksberg, B. y Sen, A. (2007). Primero la gente. Una mirada desde la ética del desarrollo a los principales problemas del mundo globalizado. Barcelona: Editorial Deusto.

Kolakowski, L. (1970). El racionalismo como ideología y ética sin código. Barcelona: Ediciones Ariel.

Kolakowski, L. (1981). La filosofía positivista. Ciencia y Filosofía. Madrid: Ediciones Cátedra S.A.
Martín-Aceña, P. (ed.) (2011). De la gran recesión del siglo xx a la gran recesión del siglo XXI. Bilbao: Fundación BBVA.

Medina, J., Becerra, S. y Castaño, P. (Septiembre de 2014). Prospectiva y política pública para el cambio estructural en América Latina y el Caribe. Santiago de Chile: Comisión Económica para América Latina y el Caribe (CEPAL), Naciones Unidas.

Mizrahi, D. (2015). Los diez países del mundo donde menos se vota. RT Sepa Más. Recuperado de https://actualidad.rt.com/ sociedad/175020-10-paises-mundo-abstencion-voto

Morin, E. (2006). Breve historia de la barbarie en Occidente. Buenos Aires: Editorial Paidós.

Organización de las Naciones Unidas (ONU). (2015). Asamblea General. Sexagésimo noveno período de sesiones. Naciones Unidas. (A/69/L.85) Recuperado de http://www.cooperacionespanola.es/sites/ default/files/agenda_2030_desarrollo_ sostenible_cooperacion_espanola_12_ ago_2015_es.pdf

Pereyra, C. (2010). El individualismo metodológico: un caso de contrarrevolución teórica. En Filosofía, historia y politica: ensayos filosóficos (1974-1988)(pp.169183). México: Editorial Fondo de Cultura Económica, Universidad Nacional Autónoma de México.

Periódico Público (2015). La esclavitud den el siglo XXI: trabajos forzados, explotación sexual y tráfico de persona. España. Recuperado de www.publico.es/sociedad/ esclavitud-siglo-xxi-trabajos-forzados. html

Red de Conocimientos Electorales (RCE). (2011). Niveles de participación electoral en América Latina. Recuperado de http:// aceproject.org/electoral-advice-es/archive/questions/replies/663253754

Romeri, J. (2006). Tratado de Libre Comercio. Análisis desde la perspectiva ideológica y del desarrollo económico. Costa Rica: Instituto de Investigaciones Jurídicas de la Universidad de Costa Rica. 
Sen, A. (1979). Equality of What? The Tanner Lecture on Human Values, (pp. 195-220), Stanford University.

Sen, A. (2000). Desarrollo y libertad. España: Editorial Planeta.

Sen, A. (2001). La desigualdad económica. México: Editorial Fondo de Cultura Económica.

Sen, A. y Kliksberg, B. (2008). Primero la gente. España: Editorial Deusto.

Serres, M. (2005). En contra de un particularismo llamado mundialización. En B. Cassen, M. Serres y A. Tarracena, Diversidad cultural y mundialización (pp. 29-57). Costa Rica: Ediciones Perro Azul.

Silva, R. (2012). Sobre los nuevos esclavos del siglo XxI. Recuperado de rafaelsilva.overblog.es-article-sobre-los-nuevos-esclavos-del-siglo-xxi-112692229.html
Stiglitz, J. (2012). El precio de la desigualdad. España: Editorial Taurus.

Tarracena, A. (2005). El dilema de no asumir la diversidad cultural propia y soñar con la globalización ajena. En B. Cassen, M. Serres y A. Tarracena, Diversidad cultural y mundialización (pp. 59-78). Costa Rica: Ediciones Perro Azul.

Therborn, G. (2015). La desigualdad mata. España: Editorial Alianza Ensayos.

Zemelman, H. (1989). Crítica epistemológica de los indicadores. Jornadas 114. Estudios Sociológicos del Colegio de México, viII (22).

Fecha de ingreso: 08/09/2017 Fecha de aprobación: 03/10/2018 
